\title{
Effects of Educational Buildings Conditions on Education Quality
}

\author{
Soheil Soleimanipirmorad, Sadiye Müjdem Vural \\ Faculty of Architecture, Eastern Mediterranean University, Famagusta, North Cyprus \\ Email:smujdem@gmail.com,Soheil_soleimanii@yahoo.com
}

How to cite this paper: Soleimanipirmorad, S., \& Vural, S. M. (2018). Effects of Educational Buildings Conditions on Education Quality. Creative Education, 9, 1978-1995.

https://doi.org/10.4236/ce.2018.913145

Received: August 29, 2018

Accepted: October 21, 2018

Published: October 24, 2018

Copyright (๑) 2018 by authors and Scientific Research Publishing Inc. This work is licensed under the Creative Commons Attribution International License (CC BY 4.0).

http://creativecommons.org/licenses/by/4.0/

(c) (i) Open Access

\begin{abstract}
Quality and productivity of education system is a major issue nowadays. There are lots of factors influencing education quality, one of these important factors is the condition and quality of the building. An educational building should provide a safe and healthy environment which students can study and work at their maximum health and productivity. Buildings may fail to provide such condition; Sick building syndrome (SBS) is one of the main reasons for this issue. Some of the common symptoms are headache, loss of concentration, runny nose, itching, dry skin and dry eyes. SBS is not always easy to recognize and lack of awareness amongst designers and users about SBS leads to problems like reducing the productivity or learning capacity of students in an educational building. In this research, signs of SBS have been observed and analyzed in the Architectural Studios of EMU (Eastern Mediterranean University) to find out if the students are suffering from SBS effects and propose some possible solutions for their improvement.
\end{abstract}

\section{Keywords}

Educational Building, SBS, Productivity, Health

\section{Introduction}

Building conditions can affect users' health and performance. Working environments and educational buildings need even more consideration towards this subject as users at these buildings spend long hours at the environment and they need to be productive. Increase of awareness and knowledge about the suitable building conditions can have important impact on students' health and productivity. Sick Building Syndrome (SBS) is a major issue at schools and educational buildings which can influence education quality (Berglund, \& Lindvall, 1986). The impact of SBS on people is a number of symptoms which have been seen 
and reported mostly at working environments like offices or educational buildings. The most common symptoms are itching, loss or lack of concentration, runny nose, headache, dry skin, lethargy, dryness or irritation of throat and dry eye (Sykes, 1988).

The schools and educational buildings have special indoor conditions (indoor air quality, visual comfort, acoustic comfort) affected by different variables, like the number and age of users, different activity types and psychological condition of the students (Goyal \& Khare, 2009).

The effects of SBS are even more important at this kind of buildings as it affects the productivity and learning capacity of students. This study is analyzing a selected case study (EMU, Faculty of Architecture, Colored building A18 and A27 classrooms) which is suspected to be affected by SBS. The aim of the study is to find out if the students are suffering from SBS and define the causes of SBS. By defining problems related with SBS, solutions will be proposed to increase the capacity and productivity of students. As a result, the awareness of SBS among students and lecturers will be increased.

\section{Effects and Causes of Sick Building Syndrome}

The "American Standards for Heating, Refrigeration and Air-Conditioning Engineers" claims that a building could be called "sick" if twenty percent or more of the users or occupants complain of suffering from discomfort symptoms for periods more than two weeks and also the affected users realize fast relief from the symptoms when they leave the building' (Passarelli, 2009). Anybody might be influenced by SBS, but usually people who spend more time at the building with SBS signs are most likely at risk of being affected. Due to complexity of SBS subject which is the reason that it is not classified as an identified sickness is that the signs and disorders disappear after twenty minutes to two hours as soon as the infected user leaves the building; that is the reason for building being called as sick, not the affected users (Jansz, 2011).

\subsection{Effects of Sick Building Syndrome}

A number of organizations have made attempts to recognize and separate the different symptoms and try to categorize them according to categories, which is related with microbe or chemical, yet the these characterizations and classifications have not been officially announced. Jack Rostron (2005) breaks up the symptoms of SBS into five common groups which are listed below:

- Mucus Membrane Irritation-influencing the nose, eyes, and throat: the most usual discontent in sick buildings is obstructed or "stuffy" nose, and sneezing and running nose is the less frequently seen case. Annoyance of throat, increased thirst and dry coughs may also appear. This could make more issues to people who are sensitive to the impacts, that is, issues for the ones who use contact lens.

- Neuropsychiatric annoyance, like dizziness, lack of concentration, confusion exhaustion and headache: The headaches which occur at this condition are 
explained as a usual heavy pressure on the head, and often do not expand into throbbing headaches or migraines.

- Skin agitation, like dryness and itchiness: as these symptoms they take place over long period of time and could simply be joined to other elements or medical conditions they are the hardest symptoms to relate to SBS.

- Asthma-like symptoms, like breathing problems and tight chest: weak indoor air qualities with a large amount of airborne dusts might make up troubles for residents without any health problem. This situation may even increase and aggravate current problems that individuals with medical conditions may experience.

- Undesirable odour (smell) and taste senses: diffusion and radiations from products which are being used in closed spaces may be distasteful for inhabitants and it might cause to nausea.

Each disorder may influence different parts of body in various ways such as: (Berglund \& Lindvall, 1986).

Eyes: Dryness, itching, tearing, redness.

Upper respiratory tract (nose and throat): Dryness, itching, nasal congestion, sneezing, nose bleed, throat pain.

Lungs: Chest tightness, drowning, dry cough, bronchitis.

Skin: Redness, dryness, general and localized itchiness.

General: Headache, weakness, difficulty in concentration, irritability, anxiety, nausea, dizziness.

\subsection{Causes of Sick Building Syndrome}

Many studies have been done in order to point out the conclusive causes of SBS but there is not any absolute conclusion or result to the issue yet. Different factors and causes have been proposed in different studies for SBS, which most of them are centralize on quality of air and ventilation system. There are also some common factors which are discussed and mentioned in most of the researches as the main contributing factors which lead to SBS which are listed as below: (Vural \& Balanl1, 2011)

- Spatial and dimensional features

- Indoor air quality

- Visual comfort

- Acoustic and noise comfort

- Psychological factors

These factors are also divided into different parts and they have different effects on users' health which are summarized at Table 1.

\section{Sick Building Syndrome and Educational Buildings}

Schools and educational buildings usually have a big number of users in compare to other facilities and buildings. Recent researches show that educational buildings have serious indoor environmental problems, and ventilation rates are 
Table 1. SBS causes and their health effects (Made by Author).

\begin{tabular}{cc}
\hline Factors leading to SBS & Health Problems \\
\hline Spatial and Dimensional Features & Injury, Stress, Lack of concentration, Depression \\
Indoor Air Quality & Fatigue, Headache, Shortness of breath, \\
eye and throat irritation, Bronchitis \\
Visual Comfort & Headache, Fatigue, Anxiety, Stress, \\
& Eye irritations, increase of blood pressure \\
Acoustic and Noise Comfort & Headache, Nausea, Dizziness, \\
& Lack of concentration, Fatigue \\
Psychological Factors & Anxiety, Stress, Lack of concentration \\
\hline
\end{tabular}

not adequate according to standards (Daisey et al., 2003).

Sick building syndrome is a major concern in all types of buildings nowadays as it affects the user in various dimensions. But it is even more important in certain cases as it directly affects the productivity and health of the users. So further studies are needed in buildings where high productivity and concentration are crucial like working environments and educational buildings.

There are different ways to solve or remove problems derived by sick building syndrome but there are also different strategies and actions to prevent it. Just like all the other diseases, it is better to prevent SBS rather than trying to solve or remove it from the effected environment. The best approach to overcome SBS in a new building is for the design team to factor out the aspects associated with the cause.

\subsection{Resolving Sick Building Syndrome in Educational Buildings}

\subsubsection{Spatial and Dimensional Features}

There are different design strategies and standards for different types of classrooms in an educational building. Some of the design considerations which are recommended for classroom design are listed below: (Carey, 2016)

- The form and orientation should match to teaching style and number of students.

- Classrooms must be in a 2:3 or 3:4 width to length ratio. Long or narrow rooms are not adequate.

- Flexibility of space is important. More space devoted to each person creates the flexibility possibility.

- Clear visibility in the classroom with no disturbance of columns.

\subsubsection{Indoor Air Quality}

Analyzing quality of indoor in schools helps can help to distinguish pollution sources and apply corrective adjustments. Outdoor pollution, ventilation equipment, furnishings, and human activities all affect indoor air quality. In school classrooms the occupancy density is high (1.8 to $2.4 \mathrm{~m}^{2} /$ person) compared to offices $\left(10 \mathrm{~m}^{2} /\right.$ person). 
Despite to design considerations and standards that has mentioned, there are also some steps to solve or remove the SBS problems caused by poor indoor air quality which are listed as below: (Seguel, Merrill, Seguel, \& Campagna, 2017)

- Source Control

- Cleaning up Dampness and Mold Signs

- Increasing Ventilation

- Ensure Proper Air Filtration/Cleaning

- Changing Old Filters

- Smoking and Spraying Inflammable Products Prohibition

\subsubsection{Visual Comfort}

Lighting condition in educational buildings and classrooms is a very important subject. A poor lighting condition can lead to SBS problem and affect students' health and productivity whereas a good lighting can improve physical and mental health of students, create a good mood and boost immune system.

According to regulations and standards, classrooms lighting should be according to variety of different zones. There are different possible lighting scenarios by combining or dimming different zones (see Figure 1). The factors that need to be considered in classroom lighting are daylight, energy efficiency and controllability (Oodith \& Parumasur, 2012).

Artificial light type should be choose wisely because it affects students' health; for classroom condition, White LED bulbs are suggested for a good lighting condition, whereas fluorescent lighting is not suggested to be used for classrooms because it may lead to different health problems for students and staff.

\subsubsection{Acoustic Comfort}

Acoustic and noise control is a key element when it comes to educational buildings and classrooms. Poor acoustic condition and unwanted noises can reduce students' concentration and learning capacity and it can lead to SBS symptoms

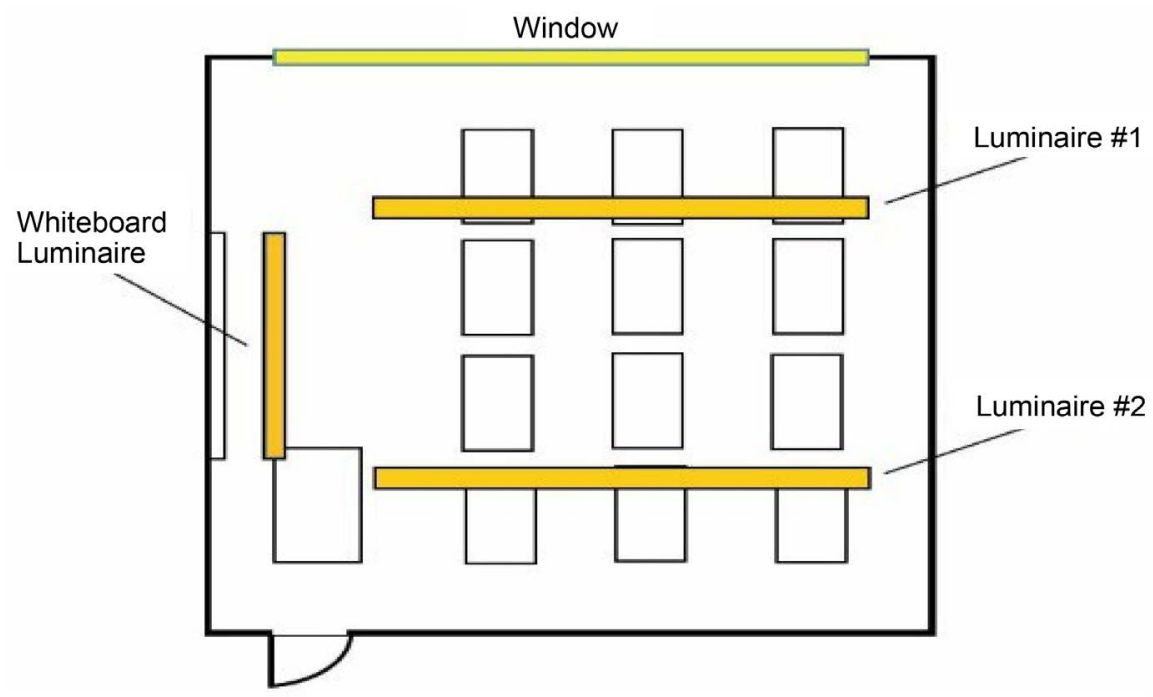

Figure 1. Zoned lighting example in classroom (URL 1). 
and make an unhealthy situation for students.

In order to solve acoustic problems in classrooms the best way is to prevent the problem rather than solving it like the other causing factors of SBS. Considering acoustics at design and construction stage are preferred by making adequate insolation in walls, thickness of the walls and even good decision of choosing location of the classroom to keep away from noisy places. But it is not an option for existing buildings, there are some solutions for classrooms with problematic acoustic conditions which can reduce or solve the problem which has mentioned below: (Ising \& Kruppa, 2004)

- Placing plants and trees to block outside noises

- Using double glazed windows

- Use some techniques for isolating sound like installing tile panels to absorb noise especially if the walls are thin

- Using carpets or materials which can absorb noise instead of hard floor

- Closing unused ducts

\subsubsection{Psychological Issues}

There are some work-related factors like high stress, excessive workload, contradiction at work and weak management system which can increase the SBS related symptoms.

Although the mentioned problems which lead to psychological disorders were about working environment, it implies for educational and teaching environments as well. Students have lots of work load, different projects and submissions that put pressure and stress on them which can increase the effects of other existing disorders.

There are some solutions in order to reduce the possibility of psychological issues like providing a safe and calm environment with less tension and good management of the organization, but in case of educational environment the main prevention approach is to solve or remove the other factors like spatial and dimensional features, indoor air quality, visual and acoustic comfort because they effect the psychology of students in various ways like anxiety, feeling stressed or lack of concentration.

\section{Analyzing Case Study}

As mentioned before educational buildings and schools are highly at risk of being affected by SBS and problems derived by it. At this study Interior Faculty of Architecture studios of EMU (Eastern Mediterranean University) at colored building (see Figure 2 and Figure 3 ) are selected as case study to be investigated and analyzed to figure out if they are affected and suffering from sick building syndrome symptoms.

The reason for choosing this building to analyze is that it is an educational building which may be a victim of SBS but also the fact that they are architecture and interior architecture studios increase the need for even more attention and 


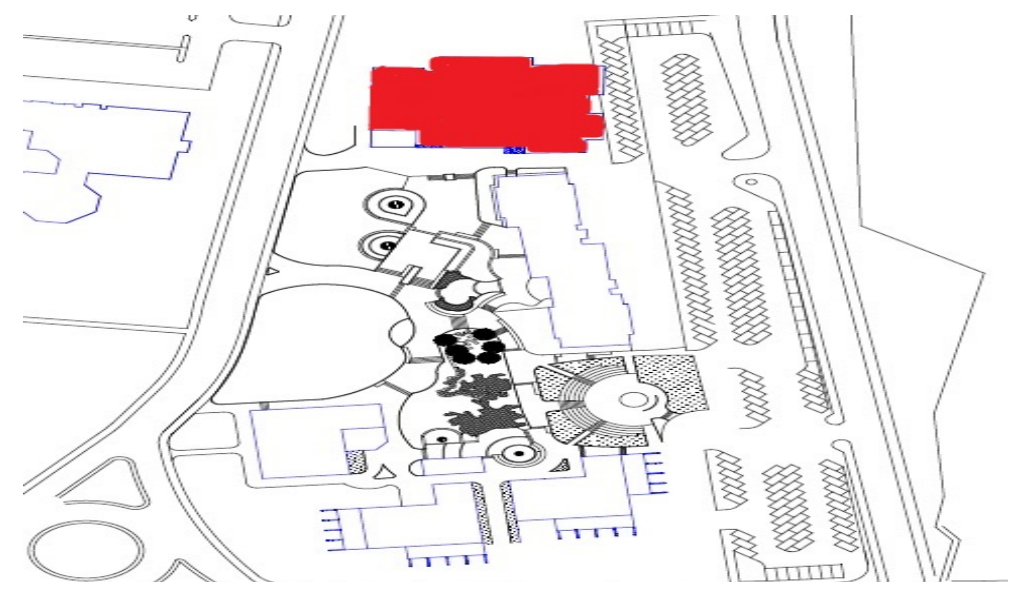

Figure 2. Position of colored building in site plan of architecture faculty.

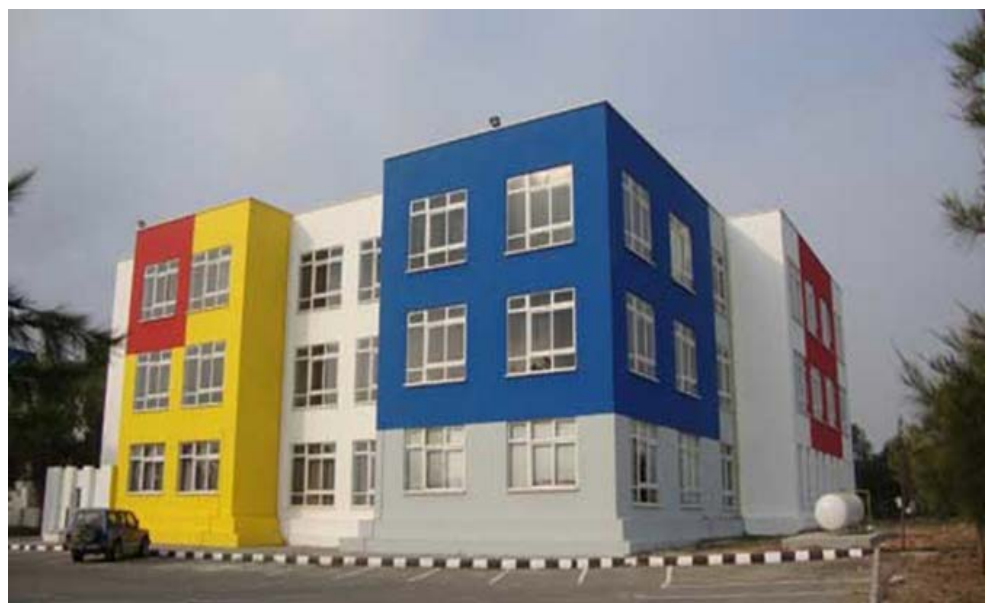

Figure 3. EMU colored building (taken by author).

consideration among other departments or educational buildings because of special conditions and activities taking place at these studios in compare to normal lecture classrooms like practical courses which involves model making and usage of different materials like glues and sprays which can pollute the environment while it also requires long hours of working in studios with high concentration.

Among different studios at Colored Building, two of the studios (A18 and A27) have been selected to be observed and look for SBS signs as they seem to be more at risk because of their condition like their location, proximity to outdoor and indoor noise and odour pollutants, long hours of usage even after the lecture hours and also recent complains of student and teachers who use these classrooms. These two studios (see Figure 4 and Figure 5) are similar in terms of shape, dimension and location but in different floors and the reason for choosing such similar cases is that they share similar characteristics and conditions so students and users of these classrooms experience similar conditions, so collected data from each classroom can be compared to the other one, and the similarity of the outcome can be a proof for accuracy of the results. 


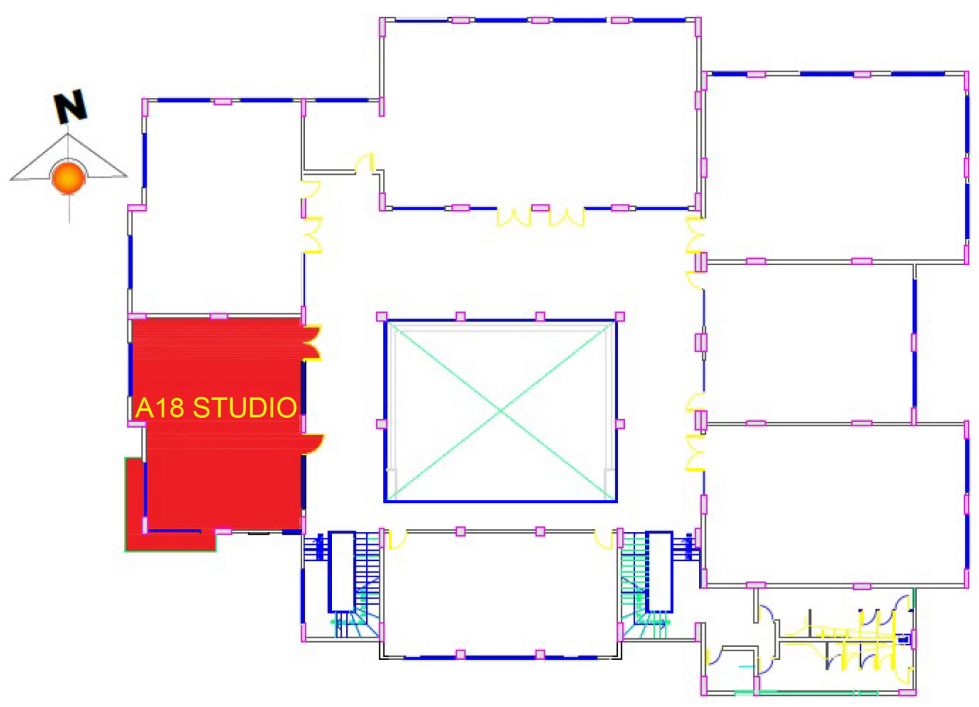

Figure 4. A18 classroom plan layout (first floor).

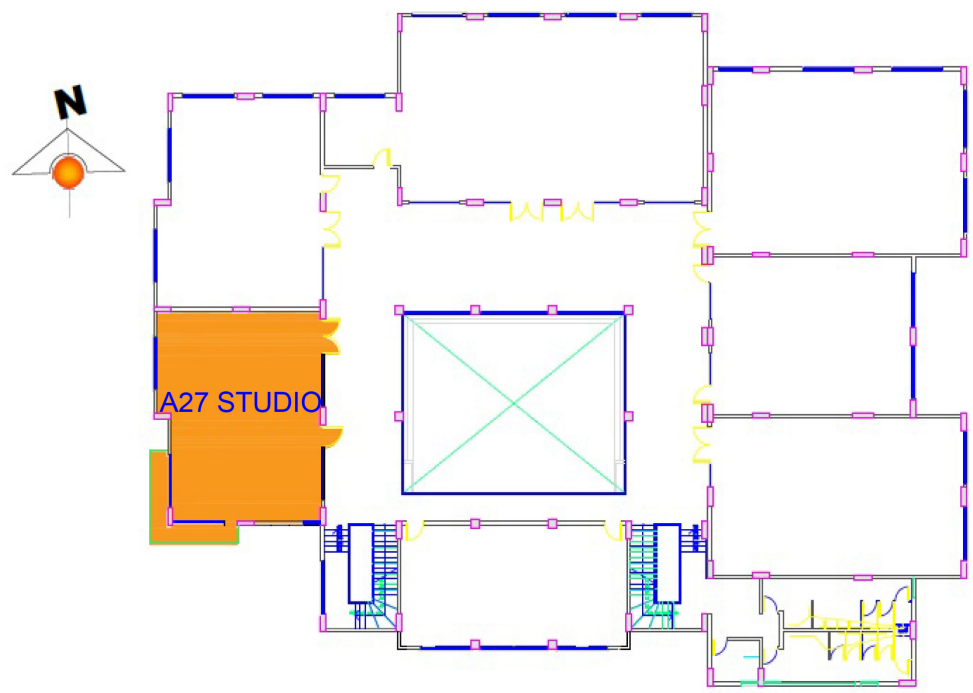

Figure 5. A27 classroom plan layout (second floor).

\subsection{Observation}

This chapter is limited to investigate those factors which have been mentioned as the most common factors of SBS according to literature which have been discussed in previous chapters and can be seek and analyzed by observation and relying on data collected from students who use the studios.

\subsubsection{Spatial and Dimensional Features}

Dimensions of a place need to be according to function of the place. There are different regulations and standards for every function which can be found at ASHRAE (The American Society of Heating, Refrigerating and Air-Conditioning Engineers). According to standards, the standard classroom size with practical courses is 25 square feet (2.3 square meters) per person. Average student number at each course being held at these classrooms is 30 students, so there is need 
for minimum 70 square meters while the area of these classrooms are 107 square meters which is adequate (See Figure 6).

Also there is no disturbing element like columns inside the classroom to disturb the visibility of the students. The dimension ratio of the classrooms are 9.6 to 11.8 meters which makes the ratio of 3:4 which is acceptable for the classroom design according to standards but the teaching stage is at the long length of the classroom which is not adequate for a good functioning classroom.

\subsubsection{Indoor Air Quality}

Air conditioning system of the selected cases (A18 and A27 studios) is not updated systems and they do not perform in an optimum level (See Figure 7). They use a central degree system which cannot be adjusted by the degree of conditions and this leads to lack of thermal comfort which is one of the main causes of SBS. A room with too high or too low temperature leads to fatigue, bad moods and productivity decrement. Bad odour is one of the common factors of SBS. They are organic or inorganic combinations which can be from inside the building or they can enter from an outdoor source. The odour from inside the building include furnishings, house or work furniture, inadequate ventilation
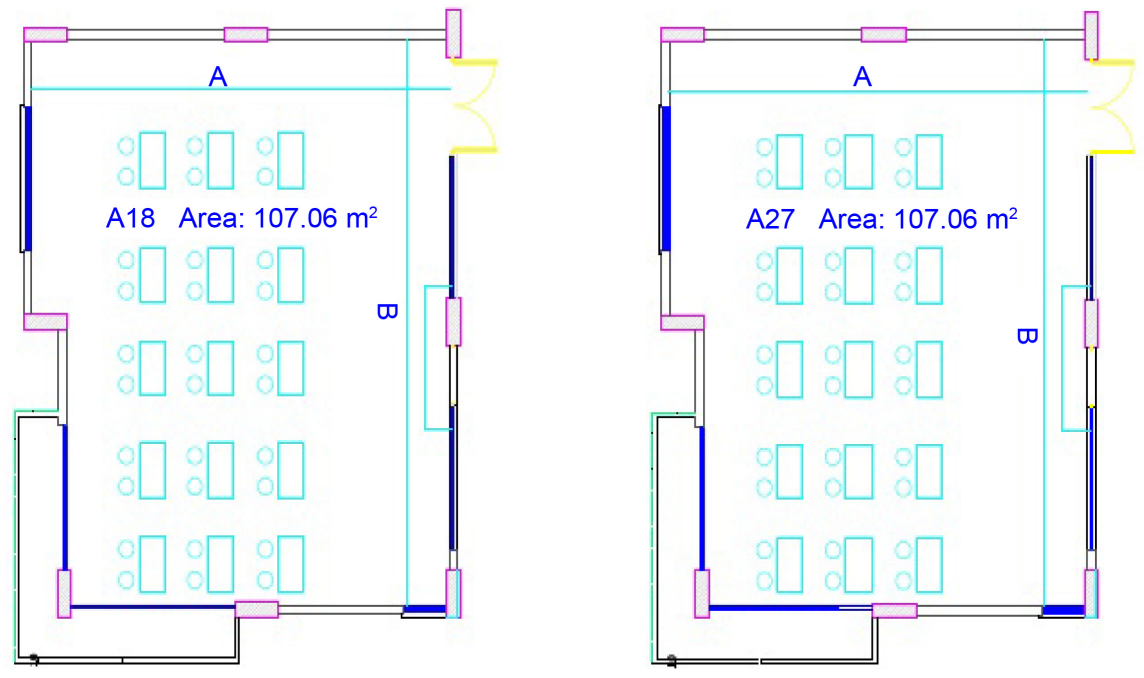

Figure 6. Area and space organization of A18 and A27 studios.

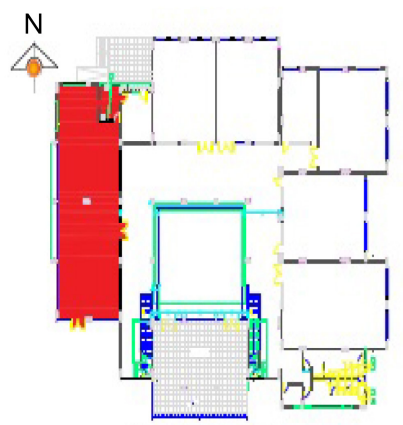

GROUND FLOOR

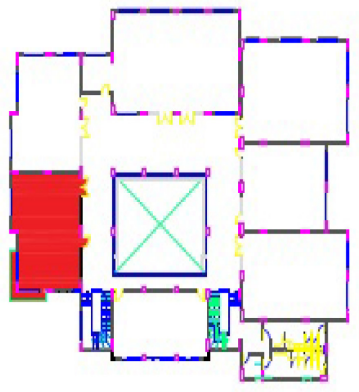

FIRST FLOOR

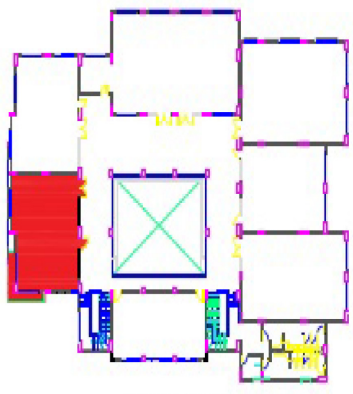

SECOND FLOOR

Figure 7. Proximity of selected case and cafeteria. 
and mould existence in the place. They can also enter the building from outdoor sources like by proximity to pollutants like streets or an environment which produces pollutants or smells.

A18 and A27 studios are suspected to be suffering from symptoms related to odour as it has the potential to be polluted by both indoor and outdoor pollutants. Poor ventilation and air-conditioning system is a cause for indoor contaminants like moulds which can even grow faster in buildings that face towards the west as the excessive sunlight in afternoon exaggerates the process. And also they are in close proximity to cafeteria of the building as they are located exactly at same side of the building in upper floors of it which draws the unpleasant odours and smell into the studios (See Figure 7).

Environmental tobacco smoke is another problem which exists at the selected studios. Although the studios and building have smoking restriction but is not being followed by some students, especially after the lecture hours when studios being used by students for working and there are no cameras or detectors to control smoking restriction.

Glues, sprays and aerosols are named Volatile Substance Abuse (VSA) or Volatile Substance Misuse (VSM) in some researches. They are made of volatile materials that are depressants, they slow down body and brain, and cause to mood changes, dizziness, red rashes on the face and intense headache.

Both studios (A18 and A27) have design lectures taking place in them which students use different glues and sprays and color sprays to make their models and sheets, this process goes on even after lecture hours during the nights by students which contributes to high level of dangerous contaminants in the space.

\subsubsection{Visual Comfort}

Studios in colored building of EMU including selected studios (A18 and A27) use fluorescent lighting like most of the buildings as it is the most common choice in the region.

Fluorescents lighting produce light when an electric current excites mercury vapor inside the glass tube. That vapor produces a short-wave ultraviolet light that causes the phosphor coating that lines the inside of the tube to glow. This lighting may lead to SBS symptoms like headache and eye irritations.

Both classroom get natural light as well. The windows are facing towards south-west and west side as it is shown at Figure 8. This direction is not proper daylight condition for a classroom; west side windows attract excessive sunlight to the classroom which is disturbing both visually and thermal comfort. Figure 9 and Figure 10 show the sunlight condition of the classrooms at different times of the day.

\subsubsection{Acoustic Comfort}

A18 and A27 studios are affected by both indoor and outdoor noises. Air conditioning systems produce a relatively loud background noise as they are not upgraded systems and it makes problem for teachers and students. 


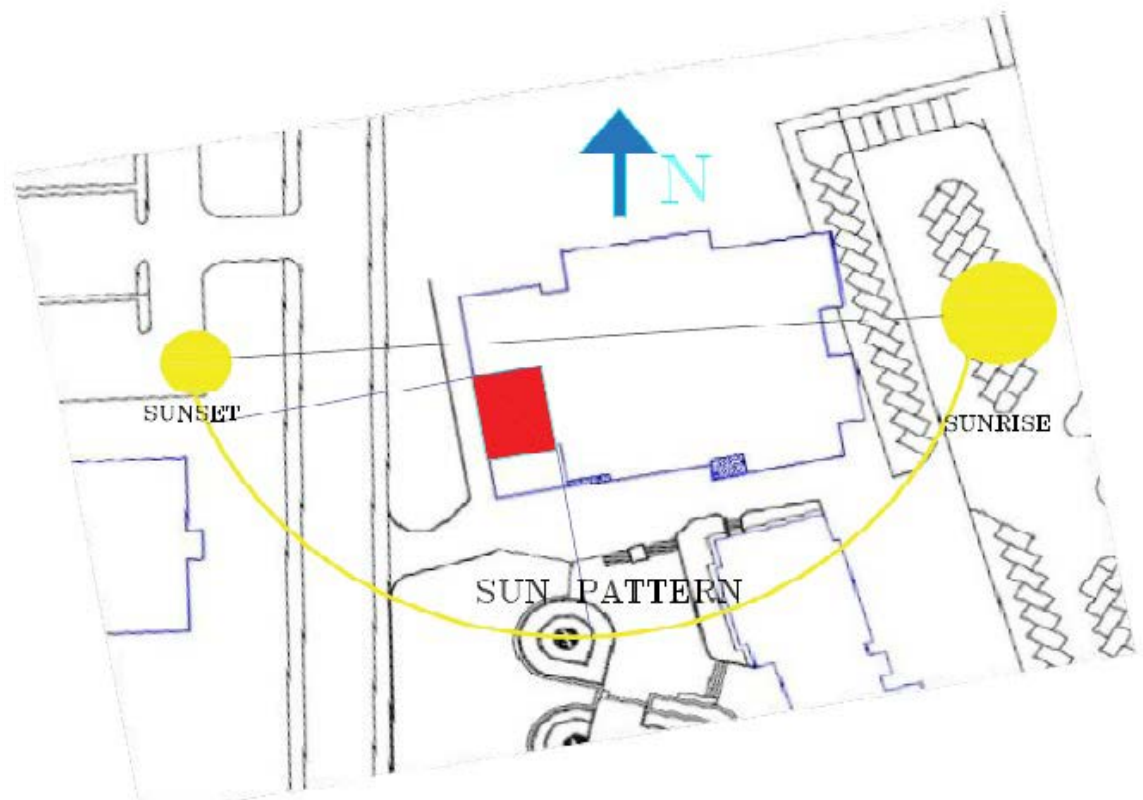

Figure 8. Sun direction path for selected cases (Made by author).

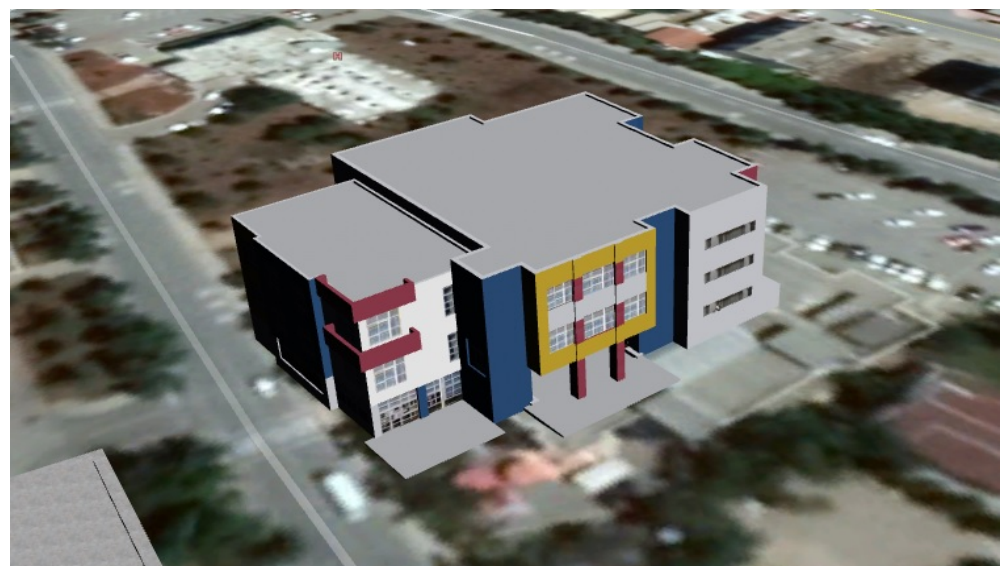

Figure 9. Daylight condition of classrooms at 11 am (Made by author).

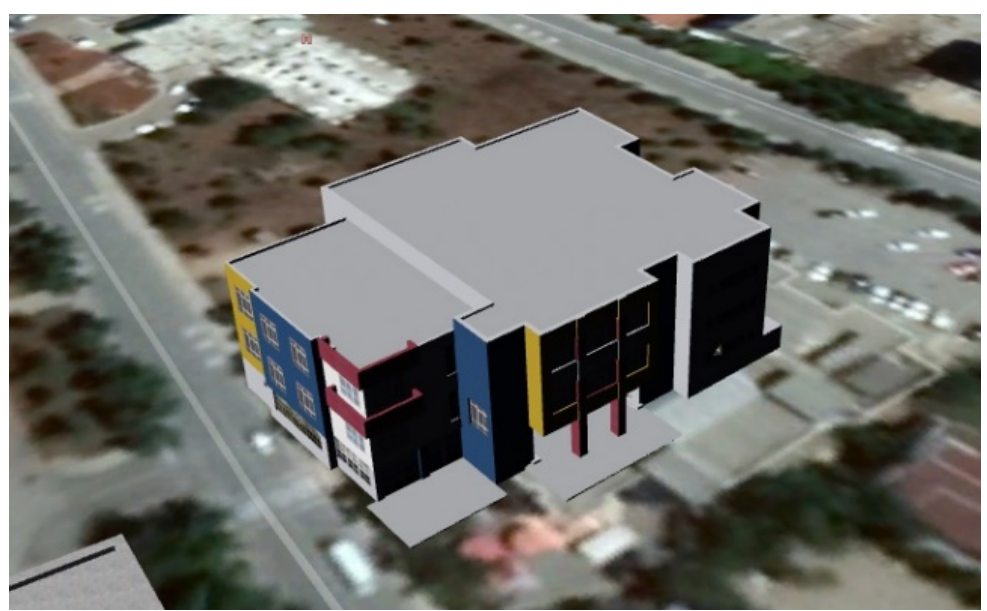

Figure 10. Daylight condition of classrooms at $2 \mathrm{pm}$ (Made by author). 
Also these two studios have windows that is facing towards cafeteria and street which produces distracting noises during studio hours which can affect students negatively and cause to lack of concentration, fatigue or headache (See Figure 11).

\subsubsection{Psychological Factors}

One of the main reasons for absence of a precise cure for sick building syndrome is that most of the attention and researches are focused on physical and environmental aspect of the problem. If the issue was only about physical aspects, there could be a cure or solution to eliminate the issue, so it is possible to indicate that SBS is not entirely a physical problem.

These factors can affect the users in different ways, they can affect the users' concentration and productivity but more importantly psychological factors can exaggerate the existing physical problems like indoor air quality or other problems in the environment, so it is crucial for user to work or study in an environment that they are psychologically satisfied.

This issue is also a major concern in educational buildings. But it is even more important in selected studios (A18 and A27) because of some special conditions that these studios have. Architecture or Interior architecture are majors that puts excessive work load and stress to students like different project deadlines and juries which takes place at the studios. This stress and workload makes a space memory on the students which makes them feel the pressure and stress while they are at these studios, the juries and practical exams usually takes place at the these studios which students already spend long hours during the week in studio hours and there is a background and reminder of the jury and exams stress and panic for them. These feelings affect the students psychologically and give them a stressful and unpleasant psychological perception which can reduce their productivity at these environments.

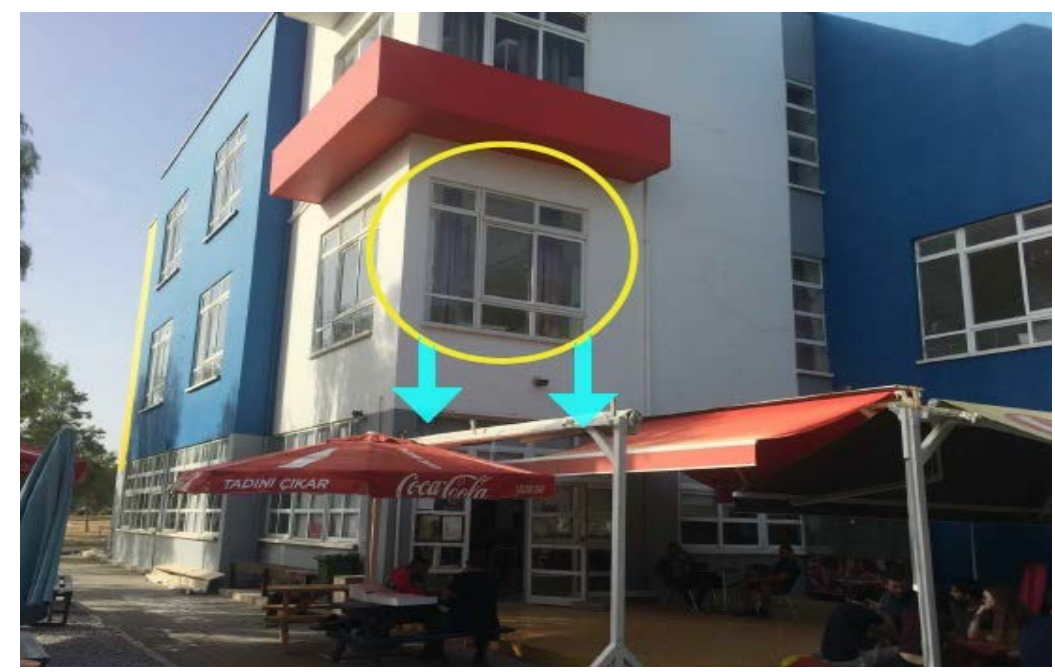

Figure 11. Exterior view of A18 classroom and cafeteria closeness (Taken by author). 


\subsubsection{Data Collection}

150 questionnaires distributed among students and teachers in each classroom (total 300) including questions about possible signs of SBS and their experience at these studios to find out if they are suffering from any disorders which may be linked to SBS symptoms. The results of some of the main questions are shown as a chart at Figures 12-17.

In order to get a more reliable result, the data must be collected from users who use the building for a relatively long time in a row like more than two hours to make sure if there is a disorder that can be related to the time spent at the building. Figure 12 shows that more than $70 \%$ of the students at both studios spend more than two hours in a row in the studios.

Despite the existence of symptoms reported at Figure 14 and Figure 15 which were mostly physical, the psychological factors must be taking into account too because they can cause or exaggerate the existing symptoms, and as mentioned before there are some factors at these studios in compare to other classrooms or departments that can lead to panic and stress like juries and project deadline which turns into a memory of space in students background. Figure 13 shows that most of the students in both studios feel the pressure and stress while they are using the studios.

How many hours do you use the classroom in a row?

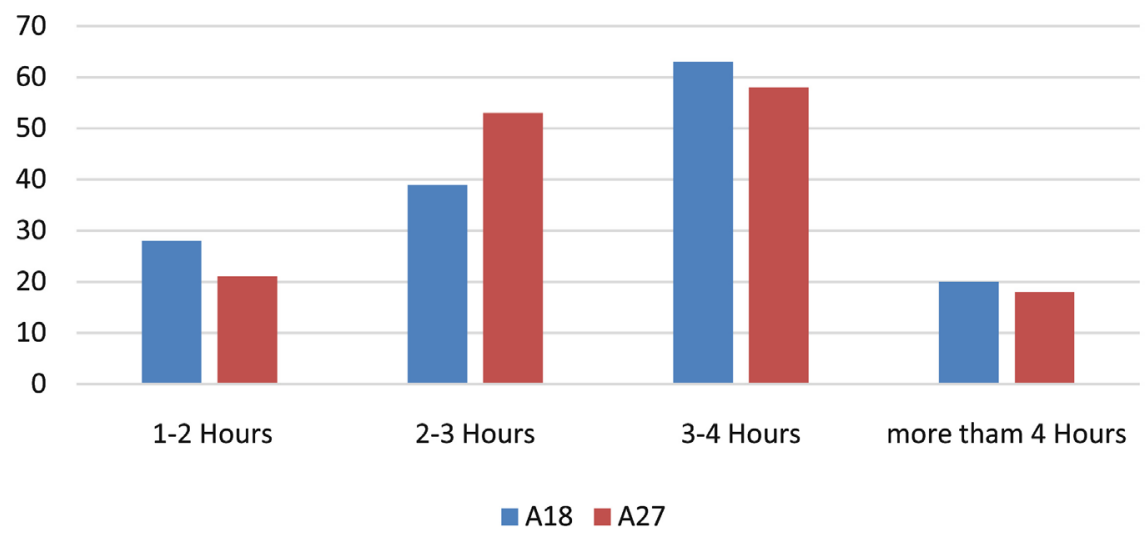

Figure 12. Duration of classroom usage by students.

Do you feel stressed or nervous while you are at this studio?

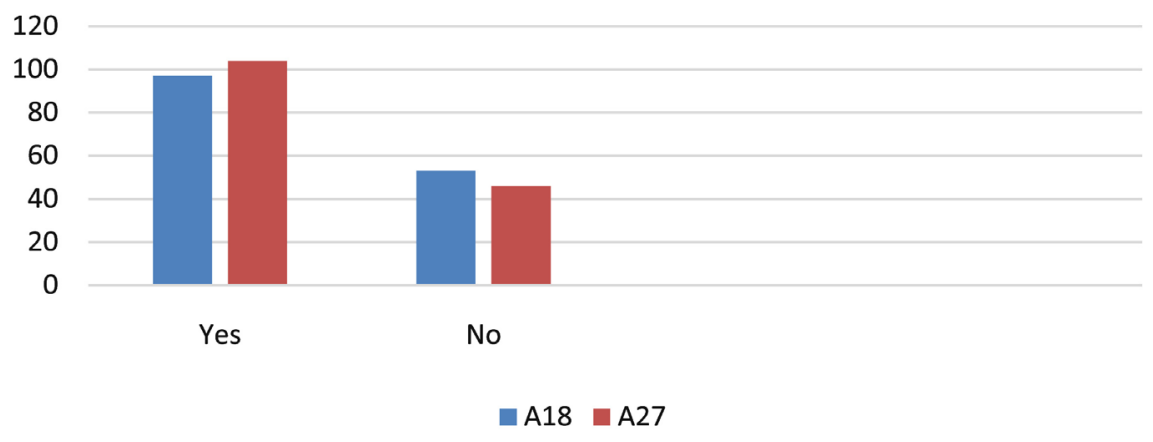

Figure 13. Stress level report from A18 and A27 students. 
Have you ever experienced any of disorders listed below while using this classroom?

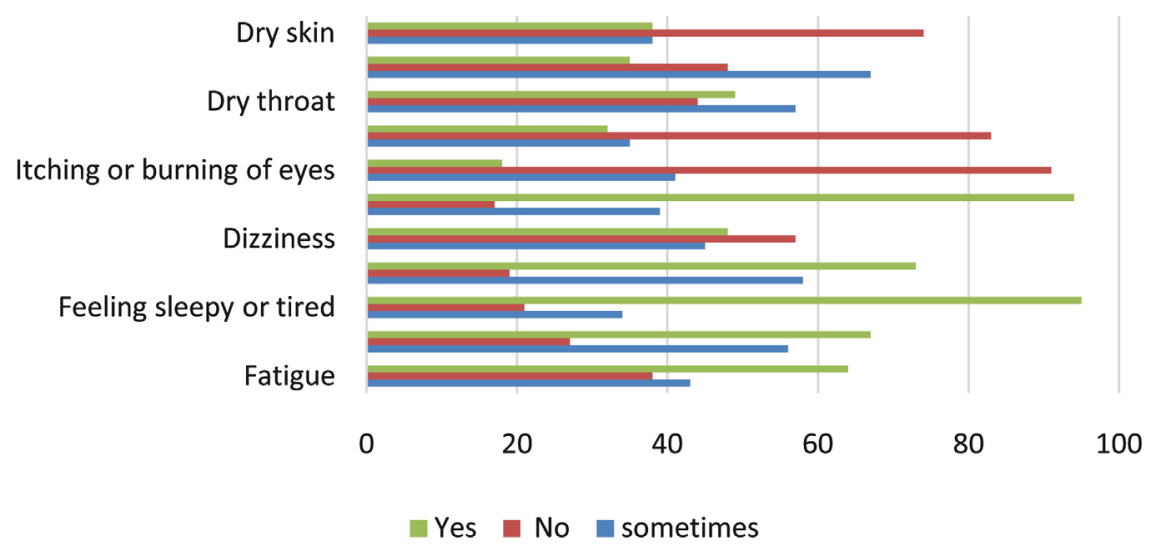

Figure 14. Complain reports from A18 studio.

Have you ever experienced any of disorders listed below while using this classroom?

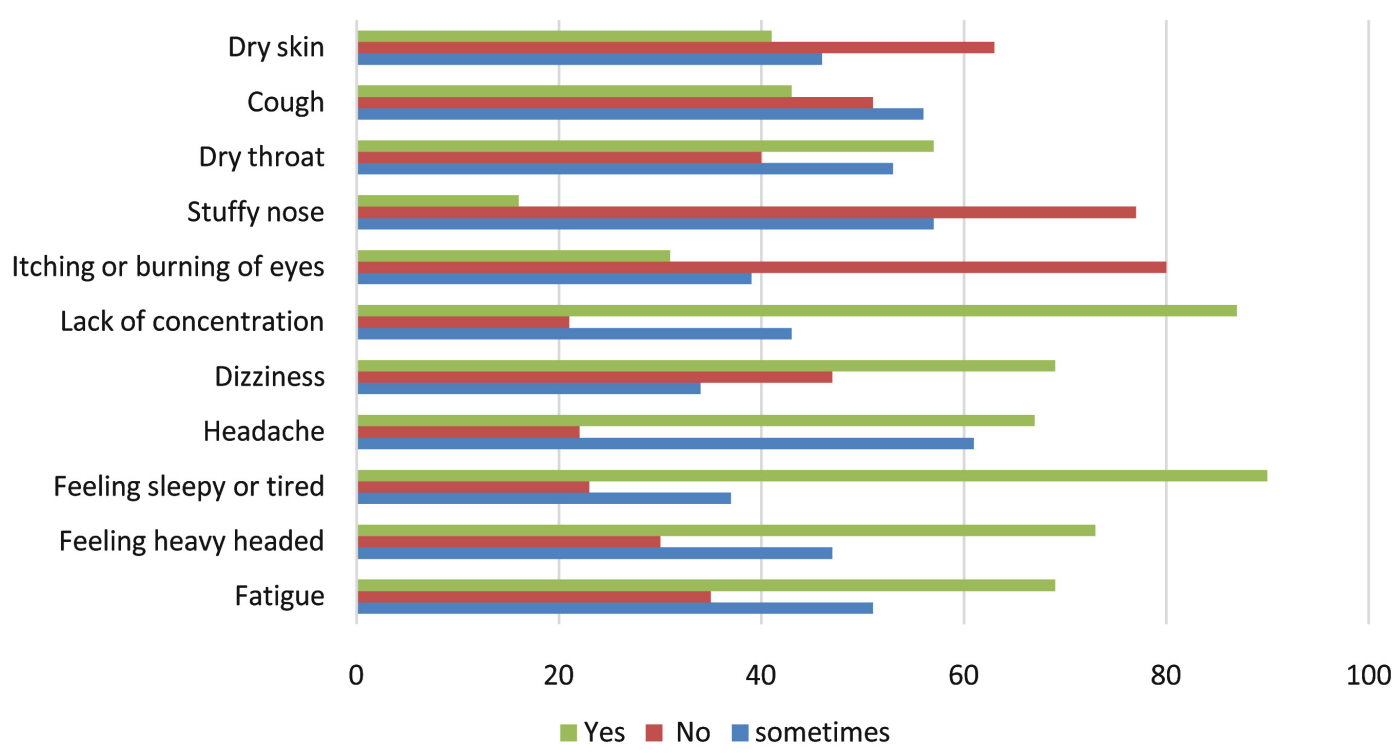

Figure 15. Complain reports from A 27 studio.

Some of the main symptoms has been collected from literature and have been asked from students of both studios to find out if they are suffering from these disorders.

The gray line in the chart shows the answers which refers to existing of the mentioned symptoms, as it is clear the gray line is coming up to $60 \%$ in most of the listed disorders in both studios which is a proof for existing of problem in studio condition and they are suspected to be called as "sick" building. Another important information which can be concluded from these charts is that the most reported symptoms in both studios is about feeling sleepy or tired and lack of concentration which is a big problem at this case as it is crucial for students to be concentrated and productive. 
Existing of the symptoms is not enough to figure out if the building is sick, there are more conditions required like if the users feel these symptoms at the particular selected environment or not which Figure 16 shows that around 67\% of the students claimed that they feel these conditions at these studios.

Also more importantly, the experienced symptoms must disappear when user leaves the environment after a while and Figure 17 shows that around $80 \%$ of students in both studio claimed that they do not feel the disorders after they leave the studio for between 10 minutes to two hours.

\subsubsection{Results of Data}

As mentioned before according to ASHREE, a building can be called "sick" if twenty percent or more of the occupants or users complain of certain disorders for periods more than two weeks and they relief from the mentioned disorders when they leave the building (Jansz, 2011).

The questionnaire distributed among students who use the studios for a semester and almost all of the symptoms were reported more than $20 \%$ by the students in both studios according to Figure 14 and Figure 15; also 67\% claimed that they experience the disorders at the particular selected studios and

Do you feel these disorders happen mostly at this particular studio?

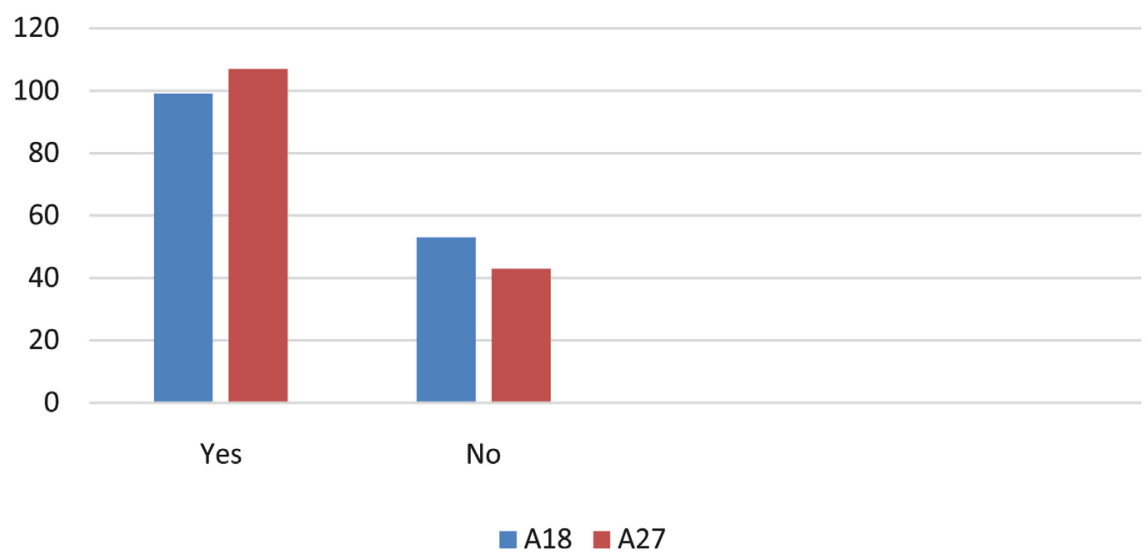

Figure 16. Location of symptoms occurrence.

Does the mentioned discomforts disappear (in 10 minutes to 2 hours) after you leave the classroom?

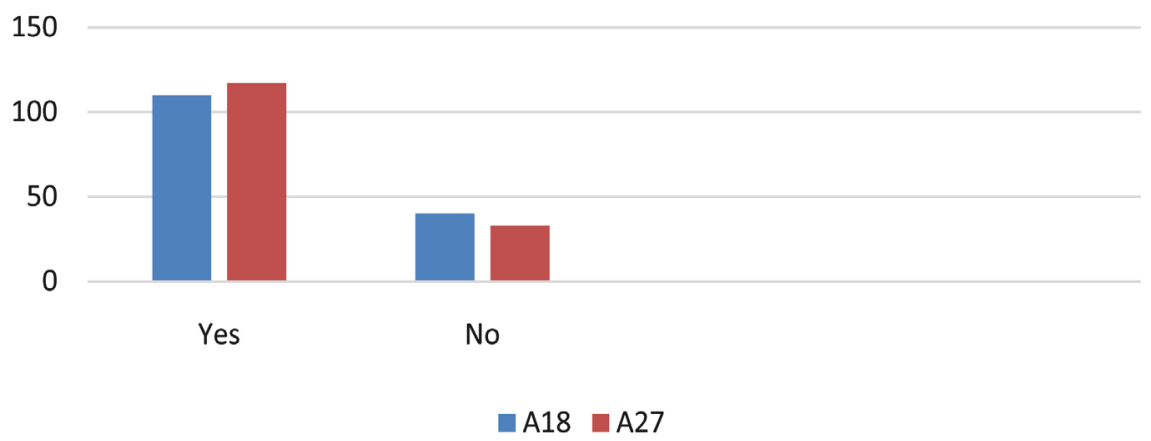

Figure 17. Symptoms relief condition at A18 and A27 classrooms. 
80\% mentioned that the symptoms disappear after a while that they leave the building which are key factors to relate the disorders to existing of SBS.

Table 2 includes the complaint reports by percentages in both studios, the orange column indicates the answer "yes" and yellow column is for answer "No", according to numbers the results for symptoms are very similar at the two studios which makes the obtained data and result more reliable.

According to definitions and information obtained from previous chapters and investigations and analysis on conditions of studios, the collected data from two studios which are quite similar to each other can conclude that these studios are suffering from SBS symptoms and the building can be listed as a "Sick Building".

\section{Conclusion}

Education is a very important subject nowadays; there are huge competitions between different schools and universities to update their education quality to provide students a condition that they can perform at their best, express their creativity and maximum productivity.

There are different approaches and strategies to provide such condition, but there are also some factors which can affect this process negatively and lead to a failure at fulfilling requirements of a healthy and comfortable environment for building users and students.

Educational buildings conditions are one of the important factors which can affect education itself. Sometimes buildings can have a negative impact on users, the term "Sick Building Syndrome" is an important example of this issue.

It has been proved that even though health problems derived by SBS are not serious, it may lead to creation of problematic conditions and consequences. In addition to distressing effects of it on people, SBS also leads to a huge decrement

Table 2. Comparison of symptoms complain at A18 and A27 classrooms (Made by author).

\begin{tabular}{ccccccc}
\hline \multirow{2}{*}{ List of Symptoms } & \multicolumn{3}{c}{ A 18} & \multicolumn{3}{c}{ A27 } \\
\cline { 2 - 6 } & Yes & No & Sometimes & Yes & No & Sometimes \\
\hline Dry skin & $526 \%$ & $449 \%$ & $25 \%$ & $27 \%$ & $42 \%$ & $31 \%$ \\
Cough & $23 \%$ & $32 \%$ & $45 \%$ & $28 \%$ & $34 \%$ & $38 \%$ \\
Stuffy nose & $33 \%$ & $29 \%$ & $38 \%$ & $38 \%$ & $26 \%$ & $36 \%$ \\
Itching or burning of eyes & $12 \%$ & $60 \%$ & $28 \%$ & $19 \%$ & $52 \%$ & $29 \%$ \\
Lack of concentration & $62 \%$ & $11 \%$ & $27 \%$ & $58 \%$ & $14 \%$ & $28 \%$ \\
Dizziness & $32 \%$ & $38 \%$ & $30 \%$ & $42 \%$ & $31 \%$ & $47 \%$ \\
Headache & $48 \%$ & $13 \%$ & $39 \%$ & $45 \%$ & $15 \%$ & $40 \%$ \\
Feeling sleepy or tired & $68 \%$ & $14 \%$ & $18 \%$ & $61 \%$ & $15 \%$ & $24 \%$ \\
Feeling heavy headed & $44 \%$ & $18 \%$ & $38 \%$ & $48 \%$ & $20 \%$ & $32 \%$ \\
Fatigue & $42 \%$ & $25 \%$ & $33 \%$ & $45 \%$ & $23 \%$ & $32 \%$ \\
\hline
\end{tabular}


of productivity, increment of absence coming from sickness and loss of precious time spent for recognizing problem and trying to solve it, which are crucial in terms of education.

Despite the importance of the issue there is not enough information and knowledge among people towards this subject, therefore this study tried to focus on this problem, study and analyze the issue from different aspects and give a more clear sight about the subject, especially on effects of SBS in educational buildings which is a major concern.

In order to show the importance of SBS subject on educational buildings, the study started with a brief information and introduction about the subject, followed by effects and causes of SBS, and continued with some possible solutions and tips to prevent or resolve SBS in educational buildings; And finally after getting to know the subject and different dimensions about it, these information were applied on selected studios (A18 and A27) used by the Interior Architecture Department studio and lecturing purposes at the colored building of the Faculty of Architecture of EMU to investigate and observe signs of SBS. According to the results of collected data it can be said that these studios are suffering from SBS disorders.

Trying overcome these symptoms generally need expert professionals and in some case might need lots of time and cost, but just like the possible simple investigations, some simple solutions might be applied as well like maintaining and refreshing indoor air quality by checking the air conditioning systems, changing lighting condition by reconsidering the lamps type being used, giving adequate and complete information to students about how smoking or using different sprays in the studio can harm their health and productivity and apply some noise and acoustic protectors at these studios. And for psychological aspects there might be need for further studies and researches to figure out how this condition can be improved because it is probably the most important factor among the others as it exaggerates the other existing problems.

\section{Acknowledgements}

The authors express their appreciation to all members of EMU Faculty of Architecture for their kind collaboration during data collection period of study.

\section{Conflicts of Interest}

The authors declare no conflicts of interest regarding the publication of this paper.

\section{References}

Berglund, B., \& Lindvall, T. (1986). Sensory Reactions to "Sick Buildings". Environment International, 12, 147-159. https://doi.org/10.1016/0160-4120(86)90025-5

Carey, K. (2016). The End of College: Creating the Future of Learning and the University of Everywhere. New York: Riverhead Books.

Daisey, J. M., Angell, W. J., \& Apte, M. G. (2003). Indoor Air Quality, Ventilation and 
Health Symptoms in Schools: An Analysis of Existing Information. Indoor Air, 13, 53-64. https://doi.org/10.1034/j.1600-0668.2003.00153.x

Goyal, R., \& Khare, M. (2009). Indoor-Outdoor Concentrations of RSPM in Classroom of a Naturally Ventilated School Building near an Urban Traffic Roadway. Atmospheric Environment, 43, 6026-6038. https://doi.org/10.1016/j.atmosenv.2009.08.031

Ising, H., \& Kruppa, B. (2004). Health Effects Caused by Noise: Evidence in the Literature from the Past 25 Years. Noise and Health, 6, 5.

Jansz, J. (2011). Theories and Knowledge about Sick Building Syndrome. In Sick Building Syndrome (pp. 25-58). Berlin, Heidelberg: Springer. https://doi.org/10.1007/978-3-642-17919-8_2

Oodith, D., \& Parumasur, S. B. (2012). The Impact of Sick Building Syndrome on Call Centre Agents' Effectiveness. Journal of Economics and Behavioral Studies, 4, 532.

Passarelli, G. R. (2009). Sick Building Syndrome: An Overview to Raise Awareness. Journal of Building Appraisal, 5, 55-66. https://doi.org/10.1057/jba.2009.20

Rostron, J. (2005). Sick Building Syndrome: Concepts, Issues and Practice. Routledge.

Seguel, J. M., Merrill, R., Seguel, D., \& Campagna, A. C. (2017). Indoor Air Quality. American Journal of Lifestyle Medicine, 11, 284-295.

https://doi.org/10.1177/1559827616653343

Sykes, J. M. (1988). Sick Building Syndrome: A Review. Merseyside, UK: Health and Safety Executive, Technology Division.

URL 1. http://lightingcontrolsassociation.org/

Vural, S. M., \& Balanl, A. (2011). Sick Building Syndrome from an Architectural Perspective. In Sick Building Syndrome (pp. 371-391). Berlin, Heidelberg: Springer. 